\title{
The analysis of ink jet printed eco-font efficiency
}

\begin{abstract}
Utilization of eco-font for office printing is one of sustainable, "green" printing concepts, which besides obvious economic benefits, as a result has a certain effect on environmental sustainability as well. The fundamental problem that this practice faces is decreased quality of text printed using eco-fonts comparing to those printed with regular fonts. The aim of this research is eco-font efficiency estimation, i.e. determination of toner usage reduction level of ink jet printed documents typed with this font type, as well as estimation of the extent humans perceive differences between text printed with eco-font and the one printed by its "non-eco" equivalent. Combining instrumental measuring method and digital image analysis, it was found that this simple principle (eco-font utilization) enables substantial toner usage reduction for an ink jet printing system, while visual test showed that visual experience of text printed using eco-font is sufficient. In addition, awareness of benefits that eco-font utilization brings, change users' attitude towards eco-font quality.
\end{abstract}

\section{KEY WORDS}

eco-font, ink jet printing, toner consumption

\author{
Rastko Milošević, \\ Uroš Nedeljković, \\ Bojan Banjanin, \\ Dragoljub Novaković, \\ Nemanja Kašiković
}

University of Novi Sad, Faculty of Technical Sciences, Department of Graphic Engineering and Design, Novi Sad, Serbia

Corresponding author: Rastko Milošević e-mail: rastko.m@uns.ac.rs

First recieved: 21.12.2015. Accepted: 10.02.2016.

\section{Introduction}

A concept of corporate social responsibility and behavior change towards sustainability and 'greener' print choices are motivated by different social, economic and environmental factors (Arikboğa, 2012; Werner, Rothenberg \& Miller, 2012).Over the past few years overall office print output has decreased with a great potential to reduce it even more, which is mostly due to utilization of different electronic devices and the emergence of various tactics which can be employed to increase the greenness of print behaviours (Bigelow et al., 2011; Werner, Rothenberg \& Miller, 2012). Some of those measures are: e-mail, projector and dual screen utilization, duplex printing, documents scanning, draft print mode utilization, single-spaced text, recycled paper, 2-up or more per page printing mode, font size below $12 \mathrm{pt}$, rational typographic choices, delayed print, no banner sheet, watermark, straggler/orphan control, margins minimization, toner-save mode/decrease ink volume, no colour, print preview, no images and eco-font utilization (Bigelow et al., 2011; Werner et al., 2012). Many companies focus on these kind of cost-effective activities, which often do not require large investments and represent very simple solutions. One of the afore mentioned measures for promotingsustainable office development is eco-font utilization, which had been undertaken by a Turkish company Türk Telekom (Arikboğa, 2012). Eco-fonts such as Spranq and InkSaver reduce ink consumption by placing holes or striations within the text, but user testing suggested that both were objectionable in terms of congeniality, i.e. the pleasure of reading (Bigelow et al., 2011). According to certain investigations rational typographic choices can lead to green printing improvements in terms of less toner consumption, where several font families were identified as toner-efficient (Garamond, Times New Roman, and Century Gothic)(Bigelow et al., 2011; Mirchandani \& Pinko, 2014). Besides font family selection, it is necessary to consider the typeface size and style for ensuring the information permanence (Možina et al., 2010). Bigelow et al. (2011) modified sans-serif open source font DejaVu and generated a new intermediate font weight called DejaVu Sans Light Thesis, using FontLab Studio software, which provided greater calculated ink 
savings, comparing to other tested font families (Helvetica, Arial, Century Gothic, Times New Roman, DejaVu: Book, Light, Extra Light) while maintaining readability.

In previous investigations researchers usually estimated ink consumption as an 'ink' coverage percentage, i.e. the number of black pixels in the digital file used to image required text in the test target, with different software tools (Photoshop and APFill Ink \& Toner Coverage Calculator)(Bigelow et al., 2011; Mirchandani \& Pinko, 2014). By basing the measure of ink consumption on pixels number in a digital image and not on the actual printed ink coverage area, the problem is abstracted from particular measures of ink jet ink or laser-printer toner on various devices, which provided a relative measure that is device-independent (Bigelow et al., 2011). The measure of printed toner coverage is known as typographic tonal density or typographic tonality. As mentioned before, it refers to the relative amount of printed ink per paper area (relative blackness of gray of type on the page). By changing different type features (typeface, type size, spacing, line length...) typographic tonality can be increased or decreased (Keyes, 1993).

\section{Factors affecting Ink Jet toner consumption}

Ink jet printing as a NIP process (Non-Impact Printing) represents one of Computer to Print technologies, where impression is generated when digital printing data arrive at the printing unit, i.e. to the ink jet nozzle system. Then, mostly liquid inks (toners) are being squirted from the nozzles directly onto the substrate, which can be made of different materials in various sizes (Petrović, Milković \& Valdec, 2013). Print quality within ink jet printing technique can be quantified in various aspects. The most important ones are color reproduction accuracy, color gamut range and print sharpness. In order to fulfill those print quality requirements, paper substrate materials designed for ink jet printing should therefore possess several qualities such as: sufficient hold out of ink on the material surface to provide high optical print density, rapid absorption of the ink vehicle liquid for fast drying in order to prevent feathering and bleeding, low colour-to-colour bleed (well-defined diffusion of the ink), low strike-through, water-fastness and light-fastness, uniform density of the paper, wicking of ink along fibers in the surface of the sheet (Durbeck, \& Sherr, 1988; Svanholm, 2007; Szentgyörgyvölgyi \& Borbély, 2015). The rate of absorption and lateral spreading of ink jet inks on paper are largely determined by the wetting, spreading, and absorption characteristics of vehicle solutions on paper. Ideally, ink vehicle should penetrate rapidly into the paper structure leaving the dyes as close as possible to the paper surface, in order to avoid smearing, running, and splatter when multiple drops arrive at the same location on the paper (Durbeck \& Sherr, 1988). Toner usage of an ink jet printer, as an important factor contributing both final print quality and overall printing costs, is affected by several factors: environmental parameters during printing process (ambient temperature $23^{\circ} \mathrm{C} \pm 2^{\circ} \mathrm{C}$ and relative humidity $50 \%$ $\pm 10 \%$ ), printing settings (print mode, printing software, driver printer firmware, computer operating system)... (Brother Industries Ltd., 2008; Jeran, 2008). Toner usage can be defined as the weight of toner consumed during the printing of one page that has a specified coverage of text and/or graphics (standard test target is a page of text with $5 \%$ coverage of the printable area, 8 " $\times 10^{\prime \prime}$ for $8.5^{\prime \prime} \times 11^{\prime \prime}$ paper). It is calculated and reported as the number of milligrams of toner per page used (mg/ page) based on the weights measured (Wyhof, 1997).

The aim of this research is determination of eco-font efficiency, i.e. estimation of the toner consumption reduction level of ink jet printed documents typed using an eco-font. Since typefaces and document layouts for office printing were not designed for the purpose of reducing toner and/or paper usage, crucial aspect, which has been covered within the paper as well, is the analysis of human visual perception of the prints, because modifications made to increase sustainability and 'greener' printing behaviour should not, but usually do decrease readability and congeniality.

\section{Method}

The samples inspected within the investigation were printed using Canon Pixima iP4200 ink jet office printer with PGI-5BK Black Ink, on standard office copy paper ( $80 \mathrm{~g} / \mathrm{m}^{2}$ uncoated wood-free paper). Before prints were made, certain basic physical and optical properties of the selected paper were measured, which results are presented in Table 1. The paper basis weight was measured according to the ISO 536 standard using ABJ-120 KERN analytical balance (International Organization for Standardization, 1995), while the paper thickness was measured according to the ISO 534 standard (International Organization for Standardization, 1988). Surface roughness of the paper samples were measured via contact profilometry method, using Surface Roughness Tester TR 200 (5 cut-off lengths of 0,8mm; RC filter; range: $\pm 40 \mu \mathrm{m}$ ), while mechanical characteristics of the selected paper (break force, break stress, stroke, and strain) were measured using Shimadzu EZ-LX compact table-top universal tester, according to TAPPI T 494 standard (Technical Association of the Pulp and Paper Industry, 1996). Then, optical properties of the paper were determined, i.e. whiteness and yellowness, using spectro-densitometer Techkon SpectroDens (measurement geometry $0 / 45^{\circ}$, illuminant D65, standard observer $2^{\circ}$ ).

Ryman Eco font (Ryman, n.d.), as one of numerous open source, free eco-fonts, was selected for the tests. Besides original eco-font which will be tested, its modified, „non-eco" match version was needed as well, in order to 
compare the toner consumption after printing process to eco-font toner consumption. Font typefaces modifications referred to enclosing of open typeface structures in order to generate font version with "filled" typeface appearance, but other typeface characteristics remained the same as the original one (Figure 1). Mentioned modifications were done using FontLab Studio 5 software. Then, two test charts were designed, both consisting of the same text elements in different sizes from 8pt to $16 \mathrm{pt}$, but in the first one text was typed using eco-font, and the other one consisted of modified, non-eco font.

\section{Table 1}

Physical and optical characteristics of the tested paper

\begin{tabular}{l|c|c}
\hline Basis weight $\left[\mathrm{g} / \mathrm{m}^{2}\right]$ & \multicolumn{2}{|c}{80} \\
\hline Thickness $[\mathrm{mm}]$ & \multicolumn{2}{|c}{0,1067} \\
\hline Specific volume $\left[\mathrm{cm}^{3} / \mathrm{g}\right]$ & \multicolumn{2}{|c}{1,33} \\
\hline Surface roughness $\left(\mathbf{R}_{\mathrm{a}}\right)[\mu \mathrm{m}]$ & 2,652 & 2,937 \\
\cline { 2 - 3 } & 120,98 & 61,36 \\
\hline Break force [N] & 4,84 & 2,45 \\
\hline Break stress [N/mm] & 2,85 & 6,58 \\
\hline Stroke [mm] & 1,90 & 4,38 \\
\hline Strain [\%] & \multicolumn{2}{|c}{124,00} \\
\hline Whiteness (WCIE) & \multicolumn{2}{|c}{$-19,61$} \\
\hline Yellowness (Y1925) & \multicolumn{2}{|c}{ CD } \\
\hline
\end{tabular}

There were the total of 40 printed A4 format ( $210 \mathrm{x}$ $297 \mathrm{~mm}$ ) paper samples, 20 printed using eco-font and the other half of the samples printed with modified, non-eco font. Initial toner consumption calculation was based on the mass measurements of the samples before and after printing process using mentioned analytical balance, where each blank paper sample was firstly measured, then printed, and right after printing process it was measured again, which was repeated for each paper sheet (under relative air humidity of $52 \%$ and air temperature of $23^{\circ} \mathrm{C}$ ). When printing and measuring process of the samples' masses were done, samples were digitalized using flatbed scanner CanoScan 5600F, on 1200 spi (using white backing, without using any correction filter).

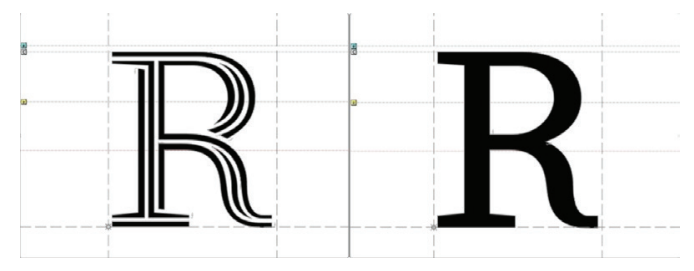

» Figure 1: Principle schema of closerange photogrammetric process

Scanned images were (TIFF and PDF file formats) needed for processing stage using different softwares (APFill Ink \& Toner Coverage Calculator and Photoshop (S6), in order to estimate toner consumption, but now based on the printed toner coverage of the paper sheet area. For visual comparison between text segments printed using both fonts, digital portable microscope ViTiny VT300 was used to generate enlarged images. Also, a visual method was employed to investigate respondents capability to distinguish the visual difference between texts printed using two different fonts. Visual test examined respondents' capability to distinguish the visual difference between text paragraphs printed with the eco (Ec) and the non-eco font (NEc). It included 12 neutral grey cardboard cards $(240 \times 100 \mathrm{~mm})$, consisted of the two same dummy text paragraphs (black text on white paper) with the same point size and typographic features (spacing, leading, number of words). Dummy text was used to direct respondents' attention only on visual differences between text printed using two different fonts. Fonts in four point sizes were used: $8 \mathrm{pt}, 9 \mathrm{pt}$, 10pt and $11 \mathrm{pt}$. For each point size, three different cardboards were used, each containing printed and cut paper samples with two paragraphs that have one of the following font combinations: Ec-Ec, NEc-NEc and Ec-NEc or NEc-Ec.

Respondents were instructed to observe each of these 12 cards separately and to state if they see any visual difference between two paragraphs with the same typographic characteristics (spacing, leading, number of words). They are instructed not to read paragraphs because of the dummy (pseudo) words, in order to be focused only on visual differences between the two paragraphs on each presented card. If participants notice any difference between the two paragraphs, they were instructed to state which one they prefer as more visually pleasing.

At the end of the visual test, respondent's were informed about characteristics of two fonts, and were asked then whether they would choose to print their documents using eco-font if they knew that this font would reduce their toner consumption. In visual test participated thirty persons (thirteen males and seventeen females), third grade students of Graphic engineering and design at the Faculty of Technical Sciences in Novi Sad, aged from 21 to 25 years old with normal to corrected vision, who have certain experience in visual arts and typography. Visual test was conducted in the darkened room using Agile Radiant Controlled Light 5 color viewing cabinet (CIE Standard Illuminant D65, a normal reading distance of 40 cm) (Faye, 1984; Legge et al., 1985a; Legge et al., 1985b).

\section{Results}

This part of the paper will present conducted analysis and obtained results of toner usage reduction which can be achieved when printing using eco-font, which was estimated via digital image analysis and using instrumental method. After those objective examinations, a visual test of the printed samples was performed. 


\section{Ink consumption analysis}

Obtained ink coverage percentages of printed samples (scans) and the two test chart PDF files (digital originals with the eco and the non-eco font) used to print the samples, are presented in Table 2. Two different softwares, APFill Ink \& Toner Coverage Calculator and Photoshop CS6, were used for the ink coverage percentage estimation. Generated APFill software results show that test chart (digital original) consisting of non-eco font has almost $33 \%$ higher ink coverage $(8,79 \%)$ comparing to the other test chart (digital original) consisting of eco-font (5,89\%). Obtained ink coverage results using Photoshop image processing, show 45,58\%higher ink coverage of test chart consisting of non-eco font $(14,13 \%)$ comparing to test chart with eco-font $(7,69 \%)$.

Regarding printed samples, the ones printed using non-eco font show higher toner coverage, i.e. higher toner consumption for 6,94\% (APFill, 13,86\%) and 7,23\% (Photoshop, 15,95\%), comparing to the samples printed with eco-font (APFill 12,96\% and Photoshop 13,83\%), which is considerably lower in comparison to previously determined test chart ink coverage results. This disproportion of obtained ink coverage ratios between test charts and printed samples is the result of printed ink jet toner spreading on the paper surface, which occurs due to absorbing and fibrous nature of the paper substrate material and rheological ink characteristics.

Table 2

Ink coverage percentages

\begin{tabular}{l|c|c}
\hline & Eco-font & Non-Eco font \\
\hline Test chart - APFill & $5,89 \%$ & $8,79 \%$ \\
\hline Test chart - Photoshop & $7,69 \%$ & $14,13 \%$ \\
\hline Samples - APFill & $12,96 \%$ & $13,86 \%$ \\
\hline Samples - Photoshop & $13,83 \%$ & $15,95 \%$ \\
\hline
\end{tabular}

In Table 3 are presented obtained average and overall mass values of the paper samples before and after printing process using two different font types (eco and non-eco), toner mass values, as well as percentage of savings when printing using eco-font.

\section{Table 3}

Masses of the samples before and after printing process

\begin{tabular}{l|c|c|c|c}
\hline & \multicolumn{2}{|c|}{ Eco-font } & \multicolumn{2}{c}{ Non-Eco font } \\
\hline Mass values & average & overall & average & overall \\
\hline Paper [g] & 4,9565 & 99,1290 & 4,9440 & 98,8796 \\
\hline Paper+toner [g] & 4,9961 & 99,9221 & 5,0091 & 100,1824 \\
\hline Toner [mg/page] & 39,7 & 793,1 & 65,1 & 1302,8 \\
\hline Saving [\%] & 39,02 & 39,12 & - & - \\
\hline
\end{tabular}

Instrumental measuring method, based on samples' mass change after the printing process, enabled more reliable results of ink jet toner consumption comparing to digital image analysis method. Obtained results indicate that by using the eco-font, the toner consumption is reduced by $39,02 \%$, for this particular text included in the test charts.

\section{Visual analysis}

In Figure 2 are presented results of the visual test, i.e. respondents' capability to distinguish the visual differences between text paragraphs printed with the eco $(\mathrm{EC})$ and the non-eco font (NEc). Results of the analysis are presented via calculated paired-comparison index values (PC-index). Thurnstone's law of comparative judgment with the statistical assumptions of a case 5 solutionwas applied to the obtaine data (respondents' grading of the text paragraphs printed using eco and non-eco-font) in order to calculate an interval scale of the samples (Engeldrum, 2000). The PC-index scales the samples from 0 to 200, where high values correspond to the samples perceived as having a good text quality, while low values correspond to samples perceived as having poorer text quality. The PC-index was calculated according to the following equation (1):

$$
P C-\text { index }=\frac{\sum_{i=1}^{n} v_{i}}{2 * n *(m-1)} * 200
$$

where $\mathrm{n}$ is the number of observers, $\mathrm{m}$ is the number of samples and vi is the value given by observer (value 2 for visually more pleasing font type, value 1 if observer do not notice any visual difference between fonts, and value 0 for visually less pleasing font type).

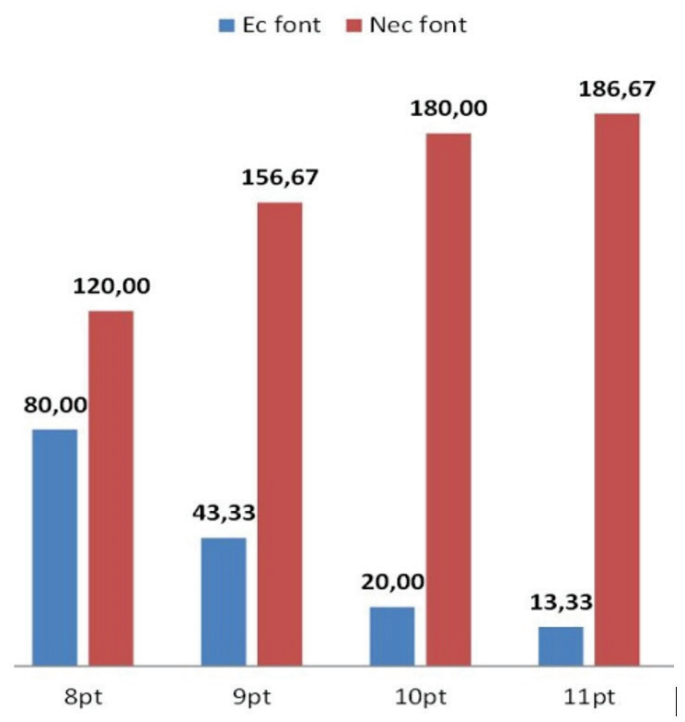

» Figure 2: Calculated PC-index for eco-font (EC) and non-eco font (NEC) for four different font sizes 
Results, i.e. calculated PC-index values, show that font size increase leads to greater perceptibility of differences between two printed font types, thus perceived text quality of the eco-font (Ec) decreases, which implies that perceived quality of text printed using non-eco font (NEc) increases (for all tested font sizes). This trend of the results was expected, because by increasing font size text becomes physically bigger, thus more eco-font features and imperfections (open typeface regions uncovered with ink that exist due to insufficient ink bleeding on the paper surface- bigger the font size, bigger the letter stroke gaps) are revealed, as well as differences between two font types becomes more noticeable (Figure 3).

\section{on on onon Eco-Iont 6pt Eco-font 8pt Eco-font 10pt Eco-font 12pt \\ onon onon \\ Non-cco font 6pt Non-cco font $8 \mathrm{pt}$ Non-cco font 10pt Non-cco font 12pt}

» Figure 3: Visual comparison of different point size text segments printed using eco-font (upper row)and non-eco font (lower row)

\section{Conclusion}

Presented investigation of ink jet toner usage reduction of printed documents typed with an eco-font, showed that it is possible to save the substantial amount of toner using this font type. Both image analysis and mass measurements indicated certain toner consumption reduction, where the later method results showed approximately $39 \%$ ink jet toner reduction with the ecofont utilization. Since typefaces for office printing were not designed with the intention to reduce toner usage, crucial aspect is that modifications made to increase sustainability do not, or as little as possible decrease readability and congeniality, if printed communication is to remain effective, because, above all, the main purpose of printing is communication (Bigelow et al., 2011). Regarding visual test, almost all participants noticed visual differences between the eco-font and the non-eco font, preferring non-eco font as visually more pleasing. Even though analysed font characteristic are on the side of non-eco font, $53,33 \%$ of the respondents (16 out of 30) indicated that they would use eco-font type if they knew that this font will save the toner. This indicates that respondents are aware of visual differences between two fonts, but when it comes to sustainable and economic benefits that users can experience using eco-font, visual differences and reading difficulties becomes less important. Another explanation of the obtained results could lie in the fact that all the participants were trained in visual communication and typography (third grade students of Graphic engineering and design), so they were prone to spotting visual differences between two font types better, thus testing participants who have no prior knowledge and experience in visual communication and typography may enable more reliable results.

Further research should be pointed towards inclusion of more printing substrate types, different ink jet printing systems, as well as in the inclusion of electrophotographic printing systems, and its toner consumption estimation in eco-font printing. Also, it would be significant to extend present visual tests to legibility and readability determination of printed eco-font.

\section{Acknowledgements}

This research was supported by the Serbian Ministry of Science and Technological Development, Grant No.:35027 "The development of software model for improvement of knowledge and production in the graphic arts industry".

\section{References}

Arikboğa, F. Ş. (2012) From Environmental Responsibilities to Green Management: Case of Turkey and a Comparative Analysis. Istanbul Üniversitesi Siyasal Bilgiler Fakültesi Dergisi. 0 (47), 31-58. Available from: http://dergipark.gov.tr/iusiyasal/ issue/629/6392 [Accessed 3rd February 2016].

Bigelow, C., Dowd-Hinkle, D. J., Horowitz, D. \& Voorhees, G. (2011) Sustainable by design: An investigation into ecologically friendly typography. Rochester, Printing Industry Center at RIT. Available from: http://scholarworks.rit.edu/cgi/viewcontent.cgi?article=1091\&context=books [Accessed 20th December 2015].

Brother Industries Ltd. (2008) Brother Genuine Monochrome Toner Cartridge Testing Method for Determining State Page Yield Based on ISO-IEC19752 Standard. Available from: http://download.brother.com/pub/ com/iso_yield/mono_19752/declared_page_yield_ iso19752_en.pdf [Accessed 20th December 2015].

Durbeck, R. C. \& Sherr, S. (eds.) (1988) Digital Output Hardcopy Devices. San Diego, Academic Press, Inc.

Engeldrum, P. (2000) Psychometric Scaling - A Toolkit for Imaging System Development. Winchester, Imcotec Press.

Faye, E. E. (1984) Clinical Low Vision. 2nd edition. Boston, Little, Brown \& Co.

International Organization for Standardization. (1988) ISO 534:1988. Paper and board: Determination of thickness and apparent bulk density or apparent sheet density. Geneva, International Organization for Standardization.

International Organization for Standardization. (1995) ISO 536:1995. Paper and board: Determination of grammage. Geneva, International Organization for Standardization.

Jeran, P. (2008) Supply standards: Past and future. 
Genève, International Organization for Standardization. Available from: http://www.iso.org/ iso/livelinkgetfile-isocs\%3Fnodeld\%3D15050486 [Accessed 15th November 2015].

Keyes, E. (1993) Typography, Color, and Information Structure. Technical Communication. 40 (4), 638-654. Available from: http://www.jstor.org/ stable/43090213 [Accessed 3rd February 2016].

Legge, G. E., Pelli, D. G., Rubin, G. S. \& Schleske, M. M. (1985a) Psychophysics of Reading-I. Normal Vision. Vision Research. 25 (2), 239-252. Available from: doi: 10.1016/00426989(85)90117-8 [Accessed 4th February 2016].

Legge, G. E., Rubin, G. S., Pelli, D. G. \& Schleske, M. M. (1985b) Psychophysics of Reading-II. Low vision. Vision Research. 25 (2), 253-265. Available from: doi: 10.1016/00426989(85)90118-X [Accessed 4th February 2016]. Mirchandani, S. \& Pinko, P. (2014) A Simple Printing Solution to Aid Deficit Reduction. Journal of Emerging Investigators. 1-5. Available from: https://www.emerginginvestigators.org/ articles/a-simple-printing-solution-to-aid-deficit-reduction [Accessed 3rd February 2016].

Možina, K., Medved, T., Rat, B.\& Bračko, S. (2010) Influence of Light on Typographic and Colorimetric Properties of Ink Jet Prints. Journal of Imaging Science and Technology. 54 (6), 60403-1-60403-8(8). Available from: doi: 10.2352/J.ImagingSci.Technol.2010.54.6.060403 [Accessed 10th January 2016]. Petrović, V., Milković, M. \& Valdec, D. (2013) Komparacija karakteristika ink-jet otisaka dobivenih vodenim, solventnim i UV bojilima. Tehnički glasnik. 7 (2), 191-197. Available from: http://hrcak. srce. hr/index.php?show=clanak\&id_clanak_ jezik=155353 [Accessed 10th January 2016].

Ryman (no date) Ryman Eco (Version 1) [Font Software] Ryman. Available from: http://www. rymaneco.co.uk/ [Accessed 8th January 2016]. Svanholm, E. (2007) Printability and Ink-Coating Interactions in Inkjet Printing. PhD thesis. Karlstad University.

Szentgyörgyvölgyi, R.\& Borbély, Á. (2015) Weather resistance of inkjet prints on plastic substrates. Journal of Graphic Engineering and Design. 6 (1), 11-14. Available from: http://www.grid.uns.ac.rs/jged/ download. php?fid=151 [Accessed 10th January 2016].

Technical Association of the Pulp and Paper Industry (1996) T 494 om-96. Tensile properties of paper and paperboard (using constant rate of elongation apparatus). Atlanta. Technical Association of the Pulp and Paper Industry.

Werner, K., Rothenberg, S. \& Miller, J. (2012) Drivers of greener print choices: an exploratory study of print consumer environmentalism. Rochester, Printing Industry Center at RIT. Available from: http://scholarworks.rit.edu/cgi/viewcontent.cgi?article=1101\& context=books [Accessed 22nd December 2015].

Wyhof, J. (1997) Page Yield of Printer Cartridges. System Support Series 112. Stanford, Static Control Components. Available from: http://www. arbikas.com/view/storage/articles/SSS112TECHPageYield.pdf [Accessed 12th November 2015]. 